\title{
KAROJBA I OKOLICA NA PRIJELAZU IZ XIX. U XX. STOLJEĆE ${ }^{1}$
}

\author{
Slaven BERTOŠA \\ Odsjek za povijest Filozofskoga fakulteta \\ Sveučilišta Jurja Dobrile u Puli \\ I. Matetića Ronjgova 1, Pula \\ sbertosa@unipu.hr
}

\author{
UDK 930.85(497.571 Karojba)“18/19““ \\ Izlaganje sa znanstvenog skupa \\ DOI https://doi.org/10.31726/via.25.1
}

\begin{abstract}
U ovom je članku autor na temelju pronađene literature proučio i opisao društvene, gospodarske, crkvene i kulturne prilike u Karojbi i njezinoj okolici (u selima Rakotule, Motovunski Novaki i Škropeti) u razdoblju osnutka škole s nastavom na hrvatskom jeziku. Vrijeme je to buđenja i jačanja hrvatske nacionalne svijesti, što se jasno odrazilo i na rezultate općinskih izbora. Postojećem gospodarskom rastu znatno je pridonijela izgradnja uskotračne željezničke pruge Parenzane, mada je taj kraj tada bio pogođen i raznim bolestima stoke i vinove loze.
\end{abstract}

Ključne riječi: Karojba, povijest, školstvo, kraj XIX. i početak XX. stoljeća

Keywords: Karojba, history, schooling, end of the 19th and beginning of the 20th century

Parole chiave: Caroiba, storia, istruzione scolastica, fine del XIX e inizio del XX secolo

\section{Političke prilike i hrvatski narodni preporod na Karojštini}

Druga polovica i kraj XIX. stoljeća vrijeme je kada se kod stanovništva počinje buditi narodna svijest. Do toga najviše dolazi zbog intenzivne djelatnosti narodnih svećenika i naprednih seljaka. Na području Karojštine razlikuju se tri razdoblja razvitka i napredovanja hrvatskoga narodnog preporoda: od 1860. do smrti biskupa Jurja Dobrile 1882., od 1882. do 1907. i od 1907. do završetka Prvoga svjetskog rata 1918. Prvi je period vrijeme u kojem na odjek preporoda snažan utjecaj ima djelovanje biskupa Dobrile kao njegove središnje ličnosti. Kao i drugdje u Istri, ali i izvan nje, u župi Karojba postao je poznat kao duhovni i preporodni vođa, koji je kao porečki i puljski biskup (1858. - 1875.) mnogo radio

1 Članak predstavlja nadopunjenu verziju izlaganja održanoga na znanstveno-stručnom skupu organiziranom u Karojbi 7. srpnja 2012. povodom 100. obljetnice osnutka tamošnje osnovne škole. Budući da do danas zbornik radova nije tiskan, autor je odlučio prilog objaviti na ovome mjestu. 
na prosvjećivanju seljaka, zalažući se za napredak sela. ${ }^{2} U$ tu je svrhu, između ostaloga, dao tiskati i svoj molitvenik Otče, budi volja Tvoja. Jednako je tako značajan i po listu Naša sloga koji se od 1870. tiska u Trstu, a bio je i istaknuti protivnik talijanskoga iredentizma, boreći se istodobno i za jednakopravnost hrvatskoga i talijanskog jezika i pisma. ${ }^{3}$

Žiteljstvo je Karojbe, Rakotula, Motovunskih Novaka i Škropeta sudjelovalo u općinskim i drugim izborima sukladno tada postojećim propisima. I prije općinskih izbora 1883., u tim je mjestima narodna svijest bila vrlo snažna. Seljaci iz prvih dvaju sela došli su na izbore u punom broju i vrlo složni, ali je pobijedila talijanska opcija. ${ }^{4}$

Kada je na općinskim izborima 1887. pobjedu odnijela Hrvatska narodna stranka, u borbi za hrvatski jezik osobito se istaknuo Ive Mikolić iz Karojbe. Sukobi su se nastavili i na izborima 1891., a 1896. opet je pobijedila Hrvatska narodna stranka. ${ }^{5}$ Nakon trijumfa talijanske stranke 1901., jedan je od izabranih općinskih savjetnika bio i Stjepan Kramar iz Rakotula. Velika se izborna pobjeda Hrvatske narodne stranke dogodila ponovno 1907., nakon primjene novoga izbornog zakona o općem i jednakom pravu glasa. ${ }^{6}$

Zahvaljujući takvim nastojanjima, popis stanovništva iz 1890. pokazao je da u Karojbi ima oko 97 \% Hrvata, 1900. bilo ih je oko 94 \%, a 1910. 95 \%.? Valja napomenuti da su na prethodna izjašnjavanja o nacionalnoj pripadnosti svakako utjecali različiti čimbenici, a među ostalima i svijest o vlastitom identitetu, društvena ovisnost, promidžba talijanskih podržavatelja i sl. Jačanjem narodne svijesti nastaju pobune protiv ovih posljednjih, kao i protiv trgovaca i zelenaša. U poznatoj pobuni 4000 istarskih seljaka, koji su 1897. išli prema Poreču prosvjedovati protiv ponašanja vlasti i talijanskih posezanja, sudjelovali su i hrvatski seljaci iz Karojbe 8 i Rakotula9.

Godine 1911., pod utjecajem Hrvatskoga katoličkog pokreta, bilo je osnovano Katoličko društvo mladeži pod nazivom »Danica«, čiji su predstavnici sudjelovali na poznatom taboru mladenačkih društava u Bermu (28. kolovoza 1912.). ${ }^{10}$ Postojalo je i mladenačko društvo u Motovunskim Novakima, utemeljeno $1913 .{ }^{11} \mathrm{U}$ tom su se periodu osnivale i različite gospodarske udruge. ${ }^{12}$

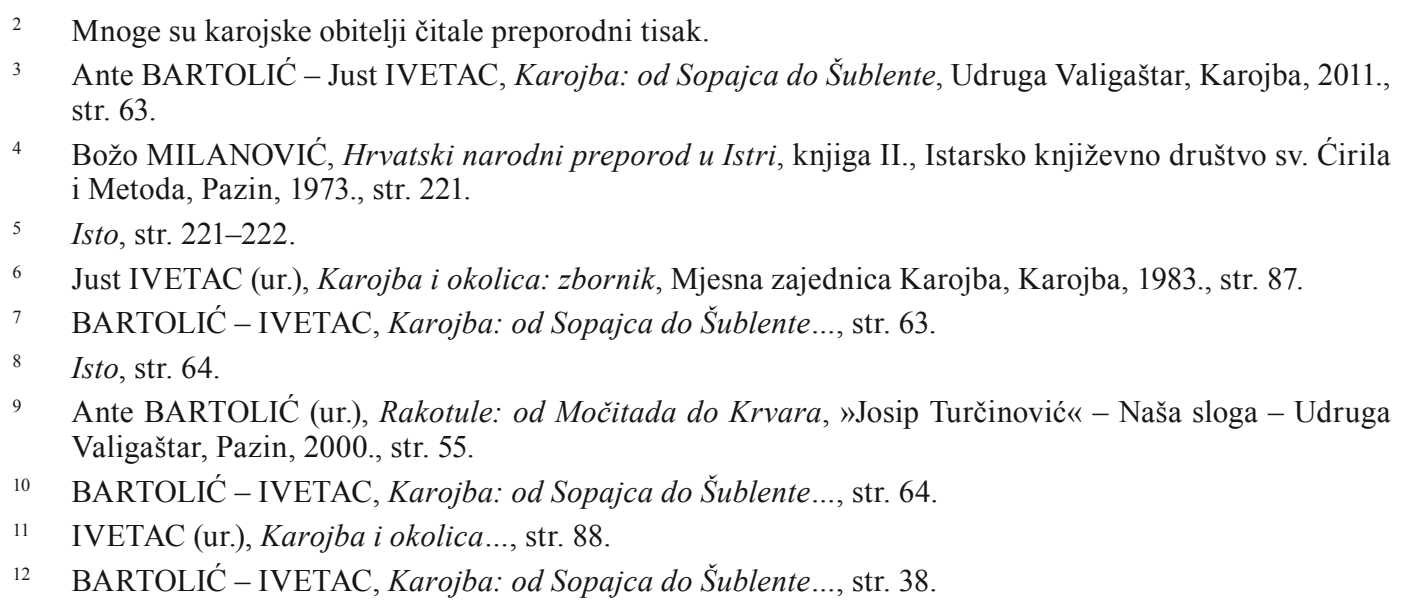


Važnu ulogu u širenju kulture i obrazovanja imala je Družba sv. Ćirila i Metoda, koja je radi jačega djelovanja u narodu i prikupljanja potrebnih sredstava po Istri osnivala svoje podružnice. Poznato je da je 1912. jedna podružnica bila i u Motovunskim Novakima. ${ }^{13}$

\section{Gospodarsko i prometno stanje: stoka, vino, željeznica}

Gospodarske nedaće koje su posljednjih desetljeća XIX. stoljeća pogodile Istru, a tako i karojsko područje, odnosile su se na smanjenu proizvodnju vina zbog raznih bolesti vinove loze (pepelnice, trsne uši i sl.) koje su uništile vinograde, ali i na bolesti stoke i nerodne godine. Bilo je i različitih klimatskih i vremenskih nepogoda (primjerice, suše i tuče). U to su vrijeme Karojci pretežito živjeli od stoke i stočnih proizvoda te od uzgoja i prerade žitarica (pšenice, ječma, raži i zobi). Porezna su davanja bila velika, a prihodi seljaka skromni pa je stanovništvo živjelo u siromaštvu. Gospodarski je oporavak uslijedio tek u posljednjem desetljeću XIX. stoljeća, kada su vinogradi obnovljeni, uz pomoć različitih savjetodavnih službi modernizirana je proizvodnja, a razvila se i trgovina stokom, vinom i drvom. ${ }^{14}$ No, od 1892. počela se primjenjivati tzv. vinska klauzula, kojom je Italija počela masovno izvoziti svoje vino na austrijsko tržište uz niže carine. ${ }^{15}$

Posljednih godina XIX. i početkom XX. stoljeća nadograđuju se mnogobrojne postojeće kuće, a intenzivno se grade i nove, od kojih neke postoje još i danas. Godine 1887. utemeljeno je Gospodarsko društvo u Motovunu, a 1899. i zadruga u Rakotulama. ${ }^{16}$ Početkom je XX. stoljeća u karojskoj župnoj kući proradila i posujilnica, koja je odobravala novčane potpore seljacima. ${ }^{17}$

Međutim, gospodarskom je rastu nedvojbeno najviše pridonijela izgradnja željezničke pruge Trst - Poreč (1900. - 1902.). ${ }^{18}$ Bila je to uskotračna pruga, duga $123 \mathrm{~km}$, sagrađena na temelju odluke austrijske vlade iz 1898., a svrha joj je bila prometno povezati naselja, gradove i općine bogata poljoprivrednoga područja Istre s Trstom kao velikim gospodarskim i potrošačkim središtem. ${ }^{19}$

Još dok su radovi na pruzi bili u tijeku, 1901. proširila se vijest da austrijska vlada namjerava postaviti dvojezične natpise na željezničkim postajama. No, odlukom povjerenstva koje je odobrilo puštanje u promet dijela pruge Buje - Poreč i na temelju uputa Ministarstva željeznica, jedino su za željezničke postaje Karojbu i Rakotule bile predviđene ploče s natpisom na hrvatskom jeziku. ${ }^{20}$

13 IVETAC (ur.), Karojba i okolica..., str. 88.

14 Međutim, procvat su vinogradarstva s početka XX. stoljeća kasnije, u doba Mussolinijeve vlasti, potiskivale i kočile mjere koje su se provodile u sklopu znamenite »borbe za žito« (battaglia del grano). BARTOLIĆ - IVETAC, Karojba: od Sopajca do Šublente..., str. 129.

15 IVETAC (ur.), Karojba i okolica..., str. 86.

16 Na ist. mj.; BARTOLIĆ (ur.), Rakotule: od Močitada do Krvara..., str. 56.

17 BARTOLIĆ - IVETAC, Karojba: od Sopajca do Šublente..., str. 64.

18 Isto, str. 63.

19 Isto, str. 159-160.

20 BARTOLIĆ (ur.), Rakotule: od Močitada do Krvara..., str. 94-95. 
Kada je 1902. puštena u promet željeznička pruga Trst - Poreč (duga ukupno 122 km), jedna od postaja na njoj bila je i Karojba, a podignuta je iznad potoka Krvara, u predjelu Kruhci. ${ }^{21}$

Između ostaloga, za izgradnju pruge koristio se kamen iz kamenoloma na desnoj strani korita potoka Krvar, nedaleko mosta i nekadašnje željezničke postaje Karojba. ${ }^{22}$ U njoj je tada postojala i sabirnica poštanskih pošiljki. ${ }^{23}$

Željeznicom se izvozilo vino, voće i povrće, drvo, stoka, kamen, ugljen i dr., a uvozili su se razni industrijski proizvodi, strojevi, alati i sl. Ljudi su vlakom, čija je prosječna brzina bila 20 - $25 \mathrm{~km} / \mathrm{sat}$, odlazili u kupovinu u Poreč, na sajmove, a emigranti u daleke zemlje. Tijekom vremena, zbog pojave novih cestovnih vozila - kamiona i autobusa - pruga je izgubila svoje značenje. Od nje su ostali pružni nasipi, mostovi i zgrade željezničkih postaja, koje su poslije pretvorene u kuće za stanovanje (iako su neke uništene, poput postaje u Karojbi). ${ }^{24}$

U prvom se desetljeću XX. stoljeća posvuda osjećao napredak, gradile su se kuće dvokatnice, otvarale su se i radile različite prodavaonice, mlin, gradila su se dvorišta sa željeznim portunima, štale za stoku, nabavljali su se željezni plugovi, kupovali su se strojevi za preradu grožđa, razvijali su se seoski obrti... Mnogi su imućniji seljaci odlazili trgovati u Poreč, Rovinj i Trst, a neki su hodočastili na Trsat, u Goricu, Padovu, Rim, Lurd (1910.) i Beč (1914.). ${ }^{25}$

Tih je godina barun Schwarz zamoljen projektirati kod sela Škropeti umjetno jezero, pomoću kojeg je vodom trebalo opskrbiti područje Poreča i Žminja. ${ }^{26}$

\section{Pitanje opskrbe vodom}

Valja istaknuti i nastojanja za poboljšanjem vodooskrbe: ovom vremenu pripadaju i prve kaptaže koje su se sačuvale do danas: jedna je 1875. izgrađena na izvoru Vrućak, a druga 1902. na Valigaštaru. ${ }^{27}$

Malo je poznato, a vrlo značajno spomenuti, da se toponim Valigaštar u suvremenim pisanim tekstovima spominje otkako ga je iz zaborava vratio i u historiografiju uveo povjesničar Miroslav Bertoša, koji je na temelju vlastitih arhivskih istraživanja spoznao iznimnu važnost ovoga lokaliteta, ne samo za srednjovjekovnu prošlost Karojbe i njezine okolice nego i čitave Istre. Pozivajući se na Istarski razvod, Bertoša ga naziva »glagoljaškim vrutkom « $\mathrm{i} » m j$ estom dogovora i pomirbe« ${ }^{28}$

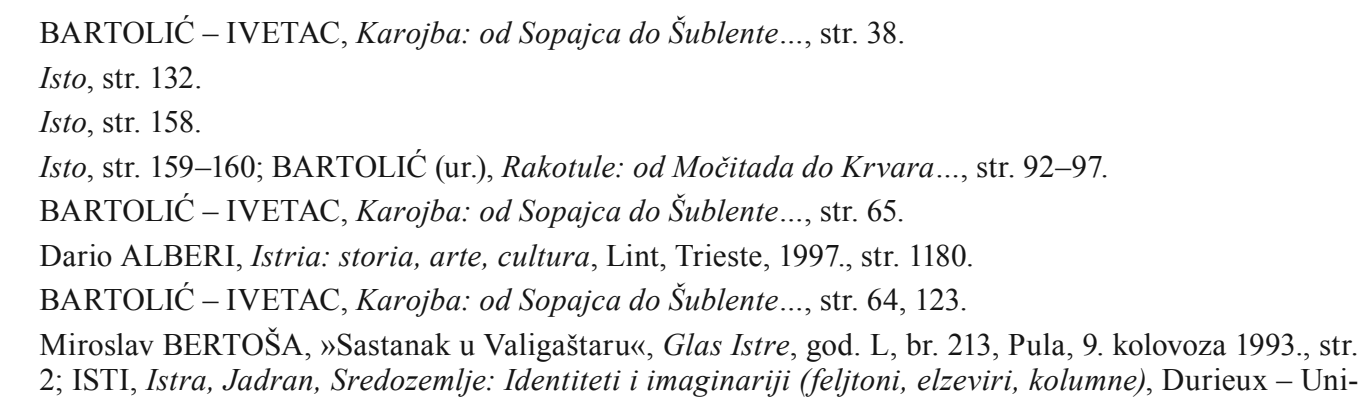


Šterna na Valigaštaru izgrađena je u doba austrijske vlasti, kada su se poticali javni radovi za zajedničko dobro, a služila je kao pričuva vode za sušno doba. Otada se s toga mjesta voda crpila kroz širok okrugao kameni otvor (grlo šterne). Limene ili drvene posude spuštale su se pomoću konopca u vodu i potezanjem rukama podizale izvan kamenoga otvora. Potom se voda prevozila do kuća. Od šterne je izgrađen kanal (dug 70 m), kojim istječe višak vode te se nižim terenom prelijeva prema maloj lokvi nazvanoj Kal. U doba niska vodostaja, obično u kolovozu, uvijek se obavljalo čišćenje šterne: ispirala se i ribala četkama te dezinficirala otopinom vapna. Na taj se način izvor Valigaštar koristio do 1938., kada je izgrađen Istarski vodovod, pa su otvorene i dvije javne slavine (špine). ${ }^{29}$

Voda iz izvora služila je za piće, kuhanje i pranje. Do kuća se obično prevozila u bačvama, na zaprežnim kolima i u brentama koje su nosili magarci. Voda iz potoka koristila se za napajanje stoke, ali i za grubo pranje posteljine (odatle toponim Perila na potoku Krvar). Voda u pučima uz kuće mogla se iskoristiti za zalijevanje vrtova, a ona u kalima i pučima u vinogradima za otapanje vapna i modre galice (verderame). Međutim, najviše se takve otopine stvaralo u posebnim bačvama vode iz izvora Vrućak i Valigaštar i odande se ona prevozila do vinograda. Takav je bio sustav vodoopskrbe prije izgradnje vodovoda. S obzirom da je svatko znao gdje se nalaze zajednički vodoopskrbni objekti te kako se održavaju i koriste, nije bilo potrebno graditi cisterne uz kuće. Zato su u Karojbi postojale samo tri privatne cisterne i dva bunara s izvorima vode (Valigaštar i Vrućak). ${ }^{30}$

\section{IV. Škole i organiziranje nastave}

Starija historiografija, odnosno autori koji su se u svojim različitim istraživačkim nastojanjima doticali pitanja školstva, uglavnom navode podatak da je prva škola u Karojbi, u kojoj se đake podučavalo na hrvatskom jeziku, bila privatna i nastavu je u njoj organizirao 1895. tadašnji župnik Emanuel Pahović. Nalazila se u prizemlju župne kuće u središtu sela. ${ }^{31}$

U Motovunskim Novakima osnovano je školsko vijeće i 1903. odlučilo se utemeljiti hrvatsku školu, no Pokrajinski odbor u Poreču suprotstavio se tada ovom prijedlogu. ${ }^{32}$ Ipak se 1908., na Družbinu inicijativu, škola počela graditi, uz svesrdnu pomoć i podršku mještana. S radom je krenula 1911. i polazili su je i učenici iz okolnih sela: Škropeti, Livaki, Lakošeljci, Pilati, Brigi i Kontići. Prvi se učitelj zvao Ivan Kosić i službovao je do 1917.33

Organizirano školovanje u Rakotulama počinje otvaranjem škole u župnom stanu, vjerojatno oko 1895. ili najkasnije 1898. U to se doba otvaraju mnoge škole koje vode svećenici pa je tako bilo i u Rakotulama, gdje je tzv. pomoćnu školu otvorio svećenik Vinko Orlandi-

versity Press, Zagreb - Dubrovnik, 2003., str. 171-174.

29 Ante BARTOLIĆ - Just IVETAC, Valigaštar, Knjižnica Na putu Istarskog razvoda 1, Naša sloga, Pazin, 1998., str. 36.

30 BARTOLIĆ - IVETAC, Karojba: od Sopajca do Šublente..., str. 122.

31 Isto, str. 38.

32 IVETAC (ur.), Karojba i okolica..., str. 88.

33 Isto, str. 216. 
ni, podrijetlom iz Dalmacije. Učinio je to na osobnu inicijativu pa je i pohađanje škole bilo uglavnom po volji učenika, odnosno njihovih roditelja, a ne po slovu zakona. Postojala je i naknada za održavanje nastave i vođenje škole: iznosila je oko 100 forinti godišnje. Godine 1909. u Rakotulama je bilo 59 djece dorasle za školu, a pohađalo ju je njih 32 (19 dječaka i 13 djevojčica). Bila je to jednorazredna škola, što po tadašnjoj terminologiji znači da je imala jednoga učitelja. Sve nam je ovo poznato iz sjećanja starijih mještana jer dokumenti o tome nisu pronađeni, a pretpostavlja se da su spaljeni dolaskom fašista $1921 .{ }^{34}$

Rakotule, dakle, nisu nikad imale školsku zgradu. Prvo obrazovanje na hrvatskom jeziku, još prije Prvoga svjetskog rata, ovdje su širili svećenici, koji su narodu ostali u vrlo lijepoj uspomeni. Nastavu su održavali - kako je navedeno - u župnom stanu i sami su nabavljali i kupovali nastavna pomagala. Učenici iz Rakotula potom su nastavu pohađali u Močibobima. ${ }^{35}$

Pripreme za izgradnju javne državne škole na kraju sela Močibobi ${ }^{36}$, uz cestu Karojba Tićan, počele su 1908., a iza te je inicijative također stajala ćirilometodska družba. Najprije je nadležnim vlastima Općine Motovun, a potom i pokrajinskoj upravi u Poreču, iznesen zahtjev za gradnju hrvatske škole. Zbog izborne pobjede Hrvatske stranke 1907. i politike austro-ugarskih vlasti o potrebi širenja pismenosti i pravima građana, donesena je konačna odluka o podizanju škole. Izgradnja je počela nakon što je postignut dogovor između Karojbe i Rakotula, koje također nisu imale školsku zgradu. Izgrađena je škola, naime, djeci iz dviju župa bila na jednakoj udaljenosti. ${ }^{37}$

Na kraju, 1912. u Močibobima je podignuta zgrada osnovne škole, čiju se 100. obljetnicu osnutka proslavilo 2012. posebnim znanstveno-stručnim skupom u Karojbi. Godine 1912. započela je nastava na hrvatskom jeziku koji je 1924. zamijenjen talijanskim, što ostaje do $1943 .{ }^{38}$ Prvi se učitelj zvao Joakim Jurčić ${ }^{39}$, a u školu se upisalo 120 učenika u dobi od 7 do 14 godina ${ }^{40} \mathrm{U}$ prizemlju je bila učionica, a na katu stan za učitelja ${ }^{41}$

Najnovija arhivska istraživanja povjesničara Stipana Trogrlića pružaju nešto drukčiju sliku. ${ }^{42}$ Iz odgovora karojskoga župnika Franje Stavelika Kotarskom školskom vijeću u Poreču iz 1905. nedvojbeno se može zaključiti da je već tada, ako ne i ranije, u naselju

\footnotetext{
34 BARTOLIĆ (ur.), Rakotule: od Močitada do Krvara ..., str. 120-121.

IVETAC (ur.), Karojba i okolica..., str. 217.

36 To je selo najbliže starom izvoru Valigaštar, a različita su tumačenja o podrijetlu njegova naziva: je li povezan s uzgojem boba (Močibobi - oni koji zalijevaju bob) ili s terminom mazzabove (Močibobi - oni koji ubijaju goveda). BARTOLIĆ - IVETAC, Valigaštar..., str. 34.

37 BARTOLIĆ - IVETAC, Karojba: od Sopajca do Šublente..., str. 264.

38 Razdoblje razvitka i napretka prekinuto je 1914., početkom Prvoga svjetskog rata.

39 Za njegova sjećanja na početak rada škole usp. IVETAC (ur.), Karojba i okolica ..., str. 219-222.

40 BARTOLIĆ - IVETAC, Karojba: od Sopajca do Šublente..., str. 264; ISTI, Valigaštar.., str. 76.

${ }^{41}$ IVETAC (ur.), Karojba i okolica ..., str. 212.

42 Spomenuti je povjesničar istraživao građu Državnoga arhiva u Pazinu.
} 
radila hrvatska pomoćna škola u kojoj se nastava, za dječake i djevojčice ${ }^{43}$, održavala samo prijepodne. ${ }^{44}$

Inspekcijsko izvješće za školsku godinu 1904./1905. navodi postojanje pomoćne škole i u Rakotulama, čiji je upravitelj bio mjesni župnik Grgur Brkan, a koja je vjerojatno djelovala do 1912., tj. do otvaranja pučke škole za Rakotule i Karojbu u Močibobima. ${ }^{45}$

Prema pisanju Naše sloge iz 1890., stanje javnih pučkih škola nije bilo dobro: unatoč činjenici da su »obćinari ${ }^{46}$ većinom Hrvati, takvih škola nije bilo. Zato su neki općinski zastupnici, poput onih iz Motovunskih Novaka i Rakotula, zatražili utemeljenje hrvatskih pučkih škola, no iako su čak bili osnovani i posebni odbori, do toga nije došlo. ${ }^{47}$

Tek je 1912., kako je već rečeno, osnovana hrvatska pučka škola u Močibobima, a odluku o njezinu otvaranju donijelo je 1908. Zemaljsko školsko vijeće u Trstu. ${ }^{48}$ Za njezina prvoga upravitelja postavljen je učitelj Aćim Jurčić, nećak trviškoga župnika Aćima (Joakima) Pilata, istaknutoga nacionalnog djelatnika među istarskim Hrvatima. ${ }^{49} \mathrm{U}$ školi su kao vjeroučitelji radili rakotulski župnik Grgur Brkan i karojski župnik Franjo Stavelik. ${ }^{50}$

U Motovunskim je Novakima od 1904. do 1911. radila jednorazredna pomoćna škola u kojoj je poučavao mjesni župnik Franjo (František) Grunt, sve dok, kako je spomenuto, 1911. nije otvorena opća pučka škola. ${ }^{51}$

Valja istaknuti činjenicu da se otvaranje hrvatskih pučkih škola na Karojštini dogodilo kao posljedica jačanja hrvatskoga nacionalnog pokreta koji se upravo na taj način mogao suprotstaviti tada postojećoj talijanizaciji. ${ }^{52}$

\section{Gradnja i obnavljanje sakralnih objekata}

U razmatranom periodu od 32 godina, župnici u Karojbi bili su: Emanuel Pahović (1869. - 1895.), rodom iz Rakotula, Josip Marek (1895. - 1899.), Ivan Cotelj (1899. - 1903.) te Franjo Stavelik (1903. - 1936.), rodom iz Moravske (umro je u Karojbi i pokopan je na seoskom groblju). ${ }^{53}$

43 Škola je, dakle, bila mješovita.

44 Stipan TROGRLIĆ, »Hrvatske škole na području Mjesne općine Motovun 1869.-1918.«, Histria - godišnjak Istarskog povijesnog društva, sv. 6., Pula, 2016., str. 41.

45 Isto, str. 42.

46 Misli se na žitelje navedene općine.

47 TROGRLIĆ, »Hrvatske škole...«, str. 47.

48 Isto, str. 48.

49 Isto, str. 49.

$50 \quad$ Isto, str. 50.

51 Isto, str. 52-53.

52 Isto, str. 35.

53 BARTOLIĆ - IVETAC, Karojba: od Sopajca do Šublente..., str. 274. 
Godine 1886. izgrađen je zvonik župne crkve sv. Marine u Motovunskim Novakima, koji je visok 30 metara. ${ }^{54}$

U stilu završne faze baroka - rokokoa, 1898. podignut je velik mramorni oltar u župnoj crkvi sv. Roka u Rakotulama. Oltaru se pristupa preko dviju stuba, a njegov je mramorni postament izveden u kombinaciji bijele i zelenkaste boje. Na spomen-ploči iza oltara stoji ovaj natpis ${ }^{55}$ Žrtvenik ovaj podigoše svojim troškom bogoljubni milosrdnici gđa. Antica udova pok. Šime Pakovića i djever joj vel.c. Ivan Paković svećenik za uprave mjesnog župnika g. Vinka Orlandinija.

Godine 1909. obavljena je dogradnja crkve sv. Magdalene u Konobarima (Gornjim Pahovićima), na blagom brežuljku zapadno od Rakotula.

Prema podatcima iz matičnih knjiga, župnici u Rakotulama u razdoblju koje obrađuje ovaj prilog bili su Vinko Orlandini (1877. - 1901.), Guglielmo Marek (1901. - 1902.) i Grgo Berkan (1902. - 1919.). ${ }^{56}$

Godine 1898., s lijeve strane ceste Močibobi - Poreč, oko 500 metara od sela, braća Grgur i Ivan Močibob dala su izgraditi zavjetnu kapelicu na Orihovici. ${ }^{57}$ Poznata je pod imenom Gospe Lurdske, a na oltaru ima kip Blažene Djevice Marije. ${ }^{58}$ Oko nje se na misnom slavlju svake godine, na blagdan sv. Petra i Pavla, ali i na misama u posebnim prilikama, okupljaju mještani iz okolice. Kapelica je obnovljena na stotu obljetnicu, 1998., i tada je na zid njezina pročelja postavljena kamena ploča s natpisom: I bivši v jutro poli maši idoše na razvodi. S lijeve je strane namještena prirodna kamena gromada, na kojoj je urezan natpis Put Istarskog razvoda, koji započinje na tome mjestu. ${ }^{59}$

Zabilježeno je da su obitelji Dagostin i Bartolić početkom XX. stoljeća, na mjestu gdje se skreće za groblje, podignule kapelu sv. Križa. Ona se redovito održava, kiti cvijećem i u njoj se moli. Temeljito je obnovljena. ${ }^{60}$

\section{Umjesto zaključka}

Od druge polovice i kraja XIX. stoljeća pa do osnutka hrvatske škole u Močibobima, broj je stanovnika u naseljima Karojštine (Karojba, Rakotule, Motovunski Novaki i Škropeti) pokazivao vrlo naglašenu prisutnost Hrvata:

\footnotetext{
54 Sama župna crkva izgrađena je nešto ranije, 1875., a posvećena je 1879. Zvonik je odvojen od crkve. Marijan BARTOLIĆ - Ivan GRAH (ur.), Crkva u Istri: osobe, mjesta i drugi podaci porečke i pulske biskupije (stanje 1. siječnja 1991. godine), II. popunjeno izdanje, Istarsko književno društvo »Juraj Dobrila« - Biskupski ordinarijat, Pazin - Poreč, 1991., str. 94.

55 Za detaljni opis oltara vidjeti: BARTOLIĆ (ur.), Rakotule: od Močitada do Krvara ..., str. 147.

56 Isto, str. 159-160.

57 BARTOLIĆ - IVETAC, Karojba: od Sopajca do Šublente..., str. 29, 64.

58 BARTOLIĆ - GRAH (ur.), Crkva u Istri..., str. 71.

59 BARTOLIĆ - IVETAC, Karojba: od Sopajca do Šublente..., str. 99.

60 Isto, str. 272.
} 


\begin{tabular}{|l|l|l|}
\hline $\begin{array}{l}\text { KAROJBA (s pripadajućim zase- } \\
\text { ocima) }^{61}\end{array}$ & \\
\hline Godina & Broj žitelja & Od toga Hrvata \\
\hline 1880. & 443 & $143-32,2 \%$ \\
\hline 1890. & 512 & $498-97,2 \%$ \\
\hline 1900. & 520 & $491-94,4 \%$ \\
\hline 1910. & 608 & $578-95 \%$ \\
\hline
\end{tabular}

\begin{tabular}{|c|c|c|}
\hline $\begin{array}{l}\text { MOTOV } \\
\text { ŠKROPE } \\
\text { ocima }^{62}\end{array}$ & & \\
\hline Godina & Broj žitelja & Od toga Hrvata \\
\hline 1880. & 622 & $158-25,4 \%$ \\
\hline 1890. & 719 & $690-95,9 \%$ \\
\hline 1900. & 740 & $739-99,7 \%$ \\
\hline 1910. & 841 & $836-99,4 \%$ \\
\hline
\end{tabular}

\begin{tabular}{|l|l|l|}
\hline $\begin{array}{l}\text { RAKOTULE (s pripadajućim } \\
\text { zaseocima) }\end{array}$ & & \\
\hline Godina & Broj žitelja & Od toga Hrvata \\
\hline 1880. & 278 & $134-48,2 \%$ \\
\hline 1890. & 316 & $316-100 \%$ \\
\hline 1900. & 326 & $326-100 \%$ \\
\hline 1910. & 349 & $344-98,5 \%$ \\
\hline
\end{tabular}

Razdoblje je prošlosti Karojbe i njezine okolice u posljednjim dvama desetljećima XIX. i u prvih dvanaest godina XX. stoljeća, tj. do osnutka hrvatske škole (okvirno od 1880. do 1912.), prepuno značajnih događaja, koji su djelomice ostavili traga i na zbivanja koja su uslijedila kasnije.

${ }_{61}$ Cadastre national de l'Istrie: d'après le recensement du ler Octobre 1945, Edition de l'Institut Adriatique, Sušak, 1946., str. 42-43.

62 Isto, str. 46-47.

63 Isto, str. $47-48$. 


\section{SAŽETAK \\ Karojba i okolica na prijelazu iz XIX. u XX. stoljeće}

Ukratko se osvrnuvši na najznačajnije događaje na Karojštini krajem XIX. i u prvih desetak godina XX. stoljeća, autor opisuje političko i gospodarsko stanje, pitanje opskrbe vodom i otvaranje škola s nastavom na hrvatskom jeziku. Piše o hrvatskom narodnom preporodu u karojskim selima te o Parenzani, željezničkoj pruzi koja je prolazila i ovim krajem. Dotiče se i gradnje i obnove sakralnih objekata spomenutoga kraja. Ističe osobitu važnost dugo zaboravljenoga lokaliteta Valigaštar, o kojem se posljednjih dvadesetak godina sve više piše, otkako je njegovo iznimno značenje, poglavito za srednjovjekovnu povijest Istre, istaknuo povjesničar Miroslav Bertoša.

\section{SUMMARY}

\section{Karojba and its surrounding at the turn of the $20^{\text {th }}$ century}

Briefly referring to the most significant events in the Karojba area at the end of the 19th century and in the first decade of the 20th century, the author describes the political and economic situation, the issue of water supply and the opening of schools with classes conducted in the Croatian language. He writes about the Croatian national revival in the villages around Karojba and about Parenzana, the railway that has passed through this region. The construction and reconstruction of sacral buildings within the mentioned area are also discussed. He emphasizes the particular importance of the long forgotten locality of Valigaštar, which has been the topic of numerous papers over the past twenty years, ever since its extraordinary significance, especially for the medieval history of Istria, was highlighted by the historian Miroslav Bertoša.

\section{RIASSUNTO}

\section{Caroiba e dintorni nel passaggio tra XIX e XX secolo}

Accennando brevemente le vicende importanti che interessavano Caroiba e dintorni alla fine del XIX secolo e nel primo decennio del XX secolo, l'autore descrive la situazione politica ed economica, la questione dell'approvvigionamento idrico e l'apertura delle scuole con lingua d'insegnamento croata. Scrive del Risorgimento nazionale croato nei villaggi di Caroiba, e di Parenzana, la linea ferroviaria che attraversava anche questo territorio. Affronta inoltre la costruzione e il rinnovo delle costruzioni sacre del citato territorio. Mette in rilievo una località per lungo tempo dimenticata, Valigaštar, di cui nell'ultima ventina d'anni si sta scrivendo sempre di più, da quando lo storico Miroslav Bertoša ha parlato della sua importanza, soprattutto per la storia dell'Istria medievale. 